\title{
[pain]Byte VR Storytelling \& Classical Ballet
}

\author{
Genevieve Smith-Nunes \\ ReadySaltedCode CIC \\ 9 The Green \\ Storrington RH20 3NL, UK \\ genevieve@readysaltedcode.org
}

\author{
Camilla Neale \\ University of Worcester \\ Henwick Grove \\ Worcester WR2 6AJ, UK \\ c.neale@worc.ac.uk
}

\begin{abstract}
This initial stage paper focuses on the Virtual Reality (VR) experience of the [pain]Byte ballet. The live and VR experience debut October 1st 2017, as part of the Brighton digital festival. Specifically, the development of the VR environment to compliment live performance by using the same choreography to create an option capture element of the VR story telling experience. Reviewing Virtual \& Alternative reality gaming \& storytelling works and the use of VR for chronic pain management (Chen, Win). Does the VR experience compare to that of the live theatre for the audience?
\end{abstract}

The data visualisations and VR environment will be continuations of the Network Simulator, [data]Storm 2015. We are visualising and comparing the pain pathway system to that of a social network. Linking pain signals to viral/negative messaging for some of the visuals. The main purpose of the pieces links to how "we" present ourselves online, these better or veiled versions of ourselves. For chronic pain sufferers, this can be daily activity in the real world. The paper concludes by identifying some future directions for the research project.

The Ballet: [pain]Byte is a data driven dance classical ballet performance and VR (virtual reality) experience. [pain]Byte, is about chronic pain and biomedical engineering, in particular the use of implanted technology - neuromodulation (Al-Kaisey et al). Using data as a medium for storytelling, what it means to be in chronic pain. The live augmented theatre and VR experience research focuses on how an audience's exposure and understanding are impacted by the difference mediums used for [pain]byte.

Virtual Reality. Motion capture. Data visualization. Networks. Pain pathway. Dance. Chronic pain.

\section{INTRODUCTION}

This paper is focusing on the virtual reality (VR) section of the third ballet [pain]. The subject for this performance is linking chronic pain and biomedical engineering with the message propagation and the presentation of self-online inn a social media network.

The Art of Computer Science is a series of data driven classical ballets using the theories and concepts of Computer Science, Using Biomedical engineering and data as the story telling with the dancers acts as data visualisation. This ballet continues the themes of network since in [data]storm. (Smith-Nunes et al. 2016)

[pain]Byte is part of an ongoing project that is a continuation and development of the previous ballet [data]storm theme of networks and signal processing. The development from the stimulation of a social network to how we present a version of ourselves online. This presentation of self to the real world is challenge for the chronic pain sufferer. The invisible pain is offered hidden by the sufferer for many different purposes. They might be for practical or social reasons. Being in pain every day has many challenges that society and the work place can often ignore or just simply be unaware.

This is a continuing partnership and collaboration between readysaltedcode CIC, Animated Data Ltd, Glaston Bridge Software, Choreographer from the University of Worcester and secondary aged Students from Battle Abbey School. Additionally, this year, The Old Market Theatre, Hove, UK. \#TOMtech: Supporting artists that use technology to hone their craft.

The ongoing project has received several awards including an International Google RISE award for Computer Science Education and three Arts Council England's, Grants for the Arts. 


\section{THEORY}

The theories and concepts for this ballet come from the worlds of medicine and social media. How neuromodulation is used to treat chronic pain sufferers to reduce their opiate intake. (Al-Kaisy et al. 2014). The social media element and of how we present ourselves online. In terms of the VR for the project we are looking how VR is being used in clinical treatments (Chin, Wren) along with VR for storytelling. VR in general as a new kind of worldwide communication (Rosedale 2016)

\subsection{CHRONIC PAIN AND BIOMEDICAL}

From the medical side of the project we have focused on implanted drug free technologies. These implantable technologies or devices use Neuromodulation. According to the International Neuromodulation Society, neuromodulation is the alteration of nerve activity through targeted delivery of a stimulus, such as electrical stimulation or chemical agents, to specific neurological sites in the body. Specifically, with regards to implanted technology or implanted pulse generator (IPG). High Frequency spinal cord stimulators (Figure 1) and the benefits to chronic pain patients. These devices differ from other types of neuromodulation as the patient does not feeling any sensation (paresthesia-free) when the device is on
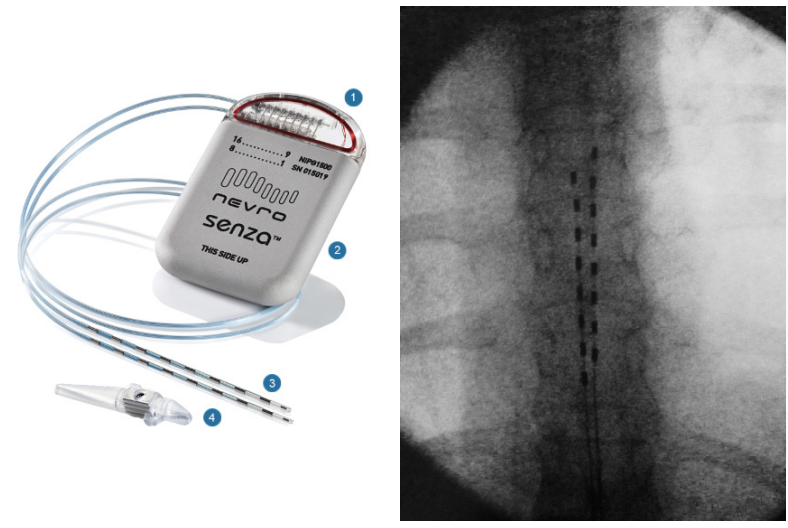

Figure 1: (Left) IPG Senza HF10, Nevro Corp, USA. (Right) Fluoroscope image, Smith-Nunes.

What is defined as a chronic pain suffer? Chronic pain is often defined as any pain lasting more than 12 weeks. Chronic pain persists, often for months or even longer. For this project we are using personal information and pain descriptions from sufferers with very long term pain, several years or more. Some of the pain sufferers have been in all their lives to some degree or another.

The impact on a sufferer's daily life due to chronic pain may include some or all of the following health implications: fatigue, sleep disturbance, decreased appetite, and mood changes, often accompany chronic pain (Breivik et al. 2006). The difficulties for sufferers is that pain is a very personal and subjective experience.

"The fact that pain is a subjective phenomenon, and pain behaviour-particularly chronic painis the result of the interaction of somatic (biological), personality (psychological), and environmental (sociological) factors" (DeGood \& Shutty 1992).

There is currently no test that can measure and locate pain with accuracy. Medical professionals must rely on the patients' description and locality of the pain. There are methods of triggering or recreating the pain in some cases.

\section{The Pain Pathway System or Gateway.}

What do we mean by pain? There are different classifications for pain. The classification listed below cover the general broad types. This list is not exclusive, but to give the reader insight in to the type of pain being portrayed in the VR experience, Neuropathic (Gravel-Sullivan et al. 2010):

Nociceptive: represents the normal response to noxious insult or injury of tissues such as skin, muscles, visceral organs, joints, tendons, or bones.

Neuropathic: with neuropathic pain, the nerve fibres themselves may be damaged, dysfunctional, or injured. These damaged nerve fibres send incorrect signals to other pain centres.

Inflammatory: a result of activation and sensitisation of the nociceptive pain pathway by a variety of mediators released at a site of tissue inflammation.

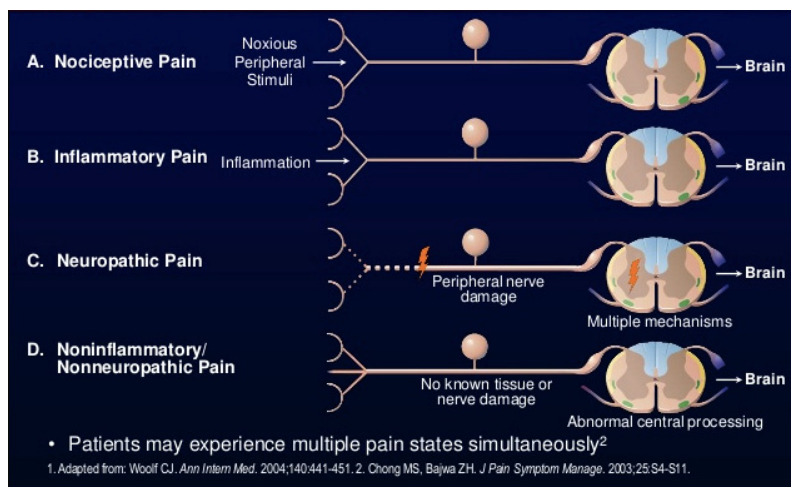

Figure 2: Types of Pain (Abbas 2010).

\subsection{PRESENTING A VERSION OF OURSELVES}

Linking and building upon the social network theory and signal processing from the previous ballet [data]storm to create a link between the internal device interrupting pains signals to the brains. This link is developed further in this ballet and refers to 
the how we present ourselves online, the selective output presented in the online world. This is like how long term chronic pain sufferers can present themselves to the outside world in real life. For the general, non-chronic pain sufferer, online user they tend to think that others have a better life than their own (Chou \& Edge 2012).

(Meyrowitz 1986) describes this "sharp distinction" between, using his terms, the 'onstage' and 'backstage' behaviours. These different sets of situations can encourage different 'onstage' (world) views compared to their 'backstage' views. Meyrowitz refers to social situations and not just the social media network setting that we are using in the ballet.

His discusses the impact of television as a breakdown of the public/ domestic division. The outside world brought into the home via the television screen.

The perception of women on and their place, or lack of place, in the world. This lack of place in the world or feelings of isolation are very common on chronic pain sufferers. In (Waugh, Byrne, \&Nicholas 2014) "Internalized Stigma in People Living With Chronic Pain" study their Initial results showed a large negative relationship between the patients with a higher level of 'internalised stigma' linked with their the lower level of pain management. There are many reasons for this an example of this is due to patients discriminatory experiences based on their pain 'validity' is being questioned.

\section{VIRTUAL REALITY}

Why VR? As this is a research project we wanted to look at audience reaction to both the live and an alternative version of the same choreography. VR allows the project to capture and use data is a different way. Recreating the dancers' movements (data of their movements) in a virtual environment that allow the visualisation of the pain to be exaggerated. As the choreography involves a certain degree of rotation and fast movement the close-up interaction may cause VR sickness. To counteract this a proximity limitation will be put in place.

By developing this VR experience provides an opportunity for other audiences' types to 'see' ballet without having seen the live performance. Giving a global access to the experience should allow for an increase in feedback regarding this experience.

\subsection{Data Capture Methods}

We decided to use marker-less systems, where possible, for the motion capture as we wanted the dancers to feel at ease with the process. As many of our dancers are under 18 the safety and risk assessment aspect of other types of systems played a part in the selection of the marker-less system. The three main data capture methods that are to be used for [pain]byte are as follows:

- Our bespoke designed and developed KinectServer(s) that work with Xbox 360 Xbox one sensors bars and RealSense Camera.

- iPi Motion Capture ${ }^{\mathrm{TM}}$ software using 2 Kinect sensors bars or a connected system of 6 PSeye camera.

- Professional motion capture suite kindly provided by the University of Hertfordshire.

Each of these different systems will output the data in various formats. All the data will be made online available for others use. We will also be adding the .bhv file format to our KinectServer to enable Blender $^{\mathrm{TM}}$ users to import the data without conversion.

The main challenge for motion capture of dancers Is ensuring the correct distance from the sensors. For the professional, this is not an issue. For the first two methods, the dancers need to be $1.5 \mathrm{~m}$ away from the front of the sensor but no more than 4 metres in depth. The stage width of the recording is much less than the theatre stage. To achieve clean data recordings, we will mark the floor to limit the dancers' movements (Figure 3 ).

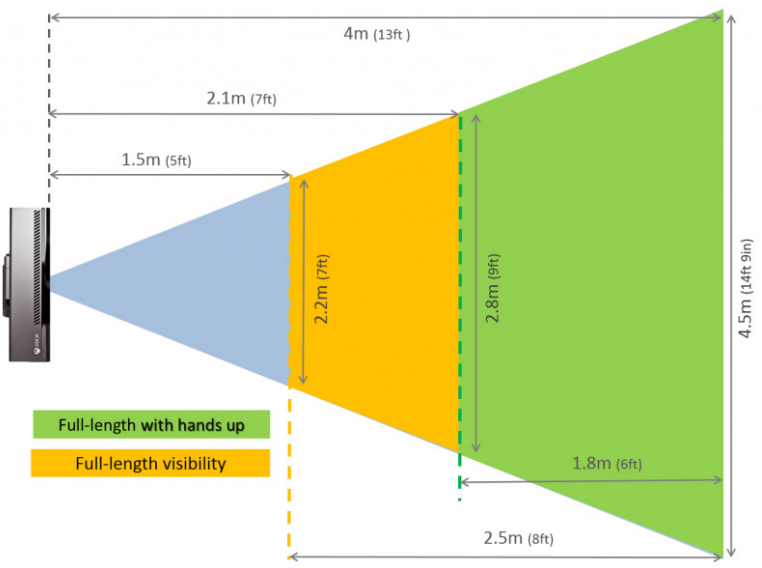

Figure 3: (c) iPi Soft 2014-15. This shows the set up with one Kinect sensor located at the front of the "stage".

\subsection{VR Technology Selection}

The initial version will be designed for Google Daydream headset (figure 4) with the view of 
further development for the HTC Vive. These particular technologies were selected due to the price point of the systems. As with many VR content there are draw backs or limitations. For the experience to be accepted on to the Google app store, it is required that this is for users 13 years and older along with VR requirements (Google Developers 2017).

The build environment for the VR experience will use Unity3D ${ }^{\mathrm{TM}}$ and Google's SDK for Daydream specifically the Unity version. There are others that are available. We selected this configuration because of the proliferation of the platform as a 3D games and VR engine. According to their own figures "Unity 'touches' 770 million gamers all over the world through games made using our engine" This figure doesn't directly reflect the number of actual developers or games/experiences being developed on the Unity3 $\mathrm{D}^{\mathrm{TM}}$ engine.

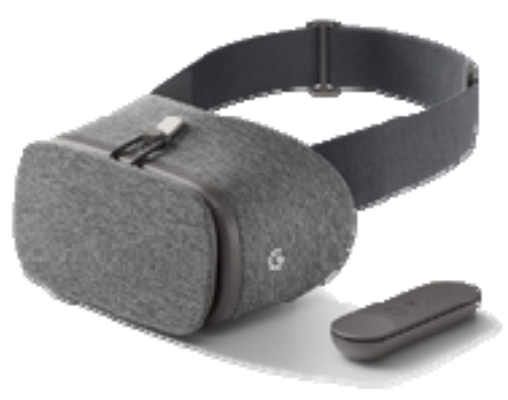

Figure 4 Google Daydream headset and controller.

As Unity3DTM has a free version for people to download was another considering factor when selecting the technology. The ability for others, particularly students to developer their own version is fundamental to this ongoing project.

\section{CHOREOGRAPHY}

At the time of writing this paper the choreography is complete and of the data capture and VR environment are both in development.

The choreography is designed to sit in both a live theatre and a virtual environment. Consideration was taken to ensure that a $360^{\circ}$ viewer would not a get a single view of the dancers. Since the choreography must be viewed by a live theatre audience, it was also important that their experience was not affected by the alterations to include this $360^{\circ}$ dimension.

To achieve this, we use the Kinect sensor depth information playing in real time from four different views. This enabled the choreographer to view the performance in an alter view showing the positions relative to the screen (the camera). The four stage positions gave greater insight into the dancers' locations, directions and spatial placement on the virtual stage that is yet to be completed. (Figure 5)

The steps and repeating motifs selected for this section of the ballet are designed to represent the 'endless' cycle of pain experienced by the sufferer. Two dancers represent the sufferer, one in pain and one presented to the 'outside or online / real' world. 5 dancers represent differ pain signals and the compounding effect that they have on the sufferer.

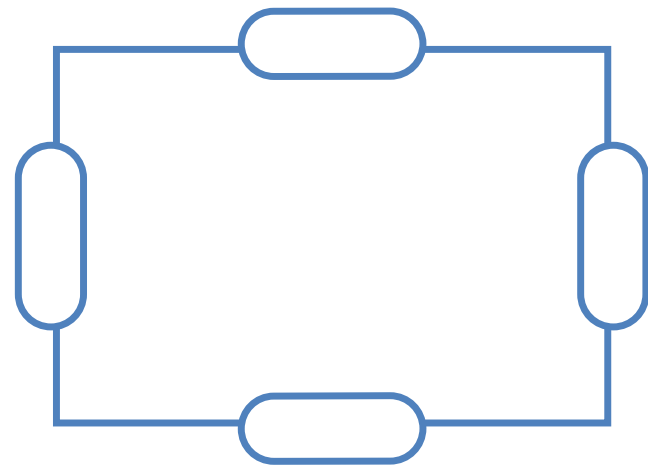

Figure 5: Kinect (depth) sensor bar set-up for four-way testing of the choreography.

The shape repeating motifs that occur throughout the piece are derived from the neurones and dendrites. The shape of the dancers' bodies and the patterns have been carefully considered in the development on the choreography. None of the ballet movements have been modified from their traditional form. Hand, body and foot placements all adhere to the classical ballet form. Some dancers are en-pointe to highlight the hidden pain through the grace and challenges of dancing en-pointe.

Many people suffer what is refer to as Complex Regional Pain Syndrome (CRPS). This is when the pain may have no discoverable cause or for some other factor. One of the impacts for CRPS sufferers is that they feel that their painful 'limb' is bigger than it really is. (Moseley 2005). We feel representing this imagery may not be achievable and detract from the experience. We decided to choreograph based on how the sufferer copes on a continual day to day basis despite the pain, the descriptors of pains and the pain signals themselves travelling through the pain pathway system. This last part links to the previous work from [data]storm.

Throughout the whole piece the "pain" dancers shadow and surround the sufferer to create this enclosed, veiled imagery. This will be enhanced for the VR experience by adding visual effects to those 'pain dancer' to exaggerate the desired impact. 


\section{FUTURE}

As the rapid development of this sector continues accessibility and cost should decrease to give more people the opportunity to have these experiences both for pleasure and for medical purposes. This is only the initial stage without final build nor user feedback. We hope to achieve a beautiful experience for the VR audience.

Further research and development will be directed towards:

- User interaction within the VR experience;

- Using a version, the VR experience within the live performance;

- Use of other VR technologies and how they differ for the user experience;

- The use of AR within a live theatre performance.

\section{REFERENCES}

Al-Kaisy, A., van Buyten, J.-P., Smet, I., Palmisani, S., Pang, D., and Smith, T. (2014) Sustained Effectiveness of $10 \mathrm{kHz}$ High-Frequency Spinal Cord Stimulation for Patients with Chronic, Low Back Pain: 24-Month Results of a Prospective Multicenter Study. Pain Medicine, 15, pp. 347-354. DOI: $\underline{10.1111 / \mathrm{pme} .12294}$

Breivik, H., Collett, B., Ventafridda, V., Cohen, R., and Gallacher, D. (2006) Survey of chronic pain in Europe: prevalence, impact on daily life, and treatment. European Journal of Pain, 10(4), pp. 287-333.

Chou, H.-T. G. and Edge, N. (2012) "They Are Happier and Having Better Lives than I Am": The Impact of Using Facebook on Perceptions of Others' Lives. Cyberpsychology, Behavior and Social Networking, 15(2), pp. 117-121, February. DOI: $10.1089 /$ cyber.2011.0324

Droso4schools (2015) L3-Neurons. https://droso4schools.wordpress.com//3-neurons/ (accessed 15 September 2017)

Fine, P. G. (2010) Chronic Pain as a Disease State. Slideshare.net.

https://www.slideshare.net/scribeofegypt/chronicpain-as-a-disease-state (accessed 22 November 2016).

Google Developers (2017) Daydream App Quality Requirements | Google VR | Google Developers. https://developers.google.com/vr/distribute/daydrea m/app-quality (accessed 11 March 2017).
Holland, P. W. and Leinhardt, S. (1971) Transitivity in structural models of small groups. Comparative Group Studies, 2, pp. 107-124.

Jensen, M. P., Chodroff, M. J., and Dworkin, R. H. (2007) The impact of neuropathic pain on healthrelated quality of life Review and implications. Neurology, 68(15), pp. 1178-1182.

Mitchell, W. J. (2003) Boundaries/Networks. In Me++: The Cyborg Self and the Networked City, pp. 7-17. Cambridge, MA: MIT Press.

Meyrowitz, J. (1986) No Sense of Place: The impact of electronic media on social behaviour. Oxford University Press.

Moseley, G. L. (2005. Distorted body image in complex regional pain syndrome. Neurology, 65(5), pp. 773-773.

Ojala, T., Häkkinen, A., Karppinen, J., Sipilä, K., Suutama, T., and Piirainen, A. (2015) Although unseen, chronic pain is real - A phenomenological study. Scandinavian Journal of Pain, Elsevier. (accessed 17 February 2017).

Projects.hsl.wisc.edu (2010) Classification of Pain - Pain Management.

http://projects.hsl.wisc.edu/GME/PainManagement/ session2.4.html (accessed 21 February 2016).

Rosedale, P. (2017) Virtual Reality: The Next Disruptor: A new kind of worldwide communication. IEEE Consumer Electronics Magazine, 6(1), pp. 48-50.

Smith-Nunes, G., Cook, P., Neale, C., and Golz, P. (2016) Data network simulator with classical ballet. In J. P. Bowen, G. Diprose, \& N. Lambert (eds.) Electronic Visualisation and the Arts (EVA London 2016), pp. 70-75. BCS, Electronic Workshops in Computing. DOI: $\underline{10.14236 / \text { ewic/EVA2016.13 }}$

Salvin, K. (2014) Understanding Neuromodulation Therapy and How It Could Benefit You? PainPathways, 17 September. https://www.painpathways.org/wpcontent/uploads/2014/09/UnderstandingNeuromodulation-Therapy-.pdf (accessed 20 January 2017).

Walther, J. B. (2007) Selective self-presentation in computer-mediated communication: Hyperpersonal dimensions of technology, language, and cognition. Computers in Human Behavior, 23(5), pp. 25382557.

Wei, H., Bizzocchi, J., and Calvert, T. (2010) Time and space in digital game storytelling. International Journal of Computer Games Technology, 2010, p. 8. DOI: $10.1155 / 2010 / 897217$ 